\title{
MISSED MESSAGE
}

\author{
And finally ...
}

\section{BY RACHEL REDDICK}

$\mathrm{T}$ his wasn't what I had planned for today. I had planned to watch the night sky. Instead, I'm waiting for the end of the world. The people on the high-orbit station tell me that I've got less than half an hour before the fireball gets here.

The low-orbit station may have been hit by debris. The high station says they're not responding to signals, so we're assuming the worst.

It's annoying. If they'd have survived, maybe we'd have a better idea of what was about to kill us all. Someone on the far side of the planet must have done something wrong. There had been rumours. One country claimed that they were constructing a faster-than-light interstellar drive, which most people assumed was a cover story for some kind of super-bomb. All that tritium, deuterium and plutonium they were collecting had to be for something. But this ... who would build this? Based on the size, one of the astronauts estimated that the explosion was nearly big enough to disrupt the entire planet. Were they playing with antimatter and lost containment? They'd have needed an immense amount of antimatter to do this. How could they get anything more than a handful of particles?

I guess we'll never know. It's an impossible disaster. An explosion like this ... it'll scour the surface clean, just as if a huge asteroid had hit. Except that we would have seen an asteroid that big coming.

No, not an asteroid. It'd need to be practically a dwarf planet. And there aren't any of those close enough to do anything to us.

As always, it's not nature that hurts us most. We're our own most effective exterminators.

I don't want to die.

An interstellar drive would be really useful right now.

But I don't have one, or even a basic launch vehicle. So I'm making the best with what I've got. I'm lucky enough, relatively speaking, to be far from the epicentre of the disaster, sitting in the control room of one of our best radio telescopes. We use ... used it to track potentially dangerous asteroids, sending out a strong pulse of radio waves and listening for the echo. We watched the skies for threats that could destroy cities. Maybe we should have been looking down, instead of up.

anything on the surface colder than molten lava. They're going to have to fire the thrusters, to avoid the debris that will soon be in orbit. Even if they do, the station isn't a closed system. They're going to run out of supplies eventually. Maybe they'll wait until they slowly starve to death. Maybe they'll decide that moving the station isn't worth the effort.

I'm glad I don't have that decision to make. I'm trying to work out if the rumbling I feel is the first sign of the approaching shockwave, or just me shaking from my own fear. I suppose I'll be signing off, whether I want to or not.

Until then, I'll keep transmitting. A last call, before we are forever silenced.

Several hundred years later...

"Huh." The young woman spun in her chair. "Jordan, can you have a look at this?"

Either way, this means I have one of the biggest and best radio transmitters at my fingertips. I may die, all of the people I have ever known and loved may die, but I can at least ensure that we will not be forgotten. That's why I'm sending this message.

Not that anyone will know how to translate it. And I suppose that there's a good chance nobody will even hear it. The telescope's radar beam is fairly narrow, as it was designed for locating asteroids. I'd aim for the neighbouring galaxy, if I could. The beam is wide enough at that distance to hit a lot of stars, and still be strong enough for someone to notice. But I can't send a radio signal through the ground.

Even if I do manage to reach an inhabited system, there's a chance they won't even be looking when the message comes by. Maybe just sending the message is enough. Enough to know that the Universe will always bear our mark, travelling forever through space. It's better than doing nothing.

I don't know what the astronauts are $\rightarrow$ NATURE.COM

Follow Futures: y @NatureFutures $f$ go.nature.com/mtoodm going to do. Most of their homes have already been vaporized. In a few minutes, there isn't going to be
"Have a look at what?" He looked at where her finger traced a series of lines on the screen, all drifting up and down chaotically.

"Do you see a signal there?"

"No, not a thing. Why?"

"Remember the unusually strong blip near the beginning of observations a couple of days ago? It wasn't far from the hydrogen lines. The short track I got that moved with Earth's rotation?"

He nodded. "Which is why it got follow-up. But the original signal didn't last very long."

"A few minutes. And when I looked there tonight, and last night, there's just nothing. Nothing at all."

Jordan gave her a sympathetic look. “That's too bad. You think it was a message?"

She tapped at the keyboard, pulling up a slice of the earlier observations. The spike was obvious. "It was narrow, it was near the hydrogen line ... but it didn't last long enough to confirm one way or another," she said sadly. "We'll probably never know." -

Rachel Reddick recently completed her graduate work in physics, and she currently teaches at Foothill Community College. She enjoys fiction and storytelling in her spare time. 